\title{
Resorts e Desenvolvimento Local na cidade de Ilha Grande, Piauí (Brasil): análise dos discursos dos atores locais
}

\section{Resorts and local development in the city of Ilha Grande - Piauí (Brazil): analysis of the local actors discourses}

\author{
Silvany Nascimento da Silva (SILVA, S. N. da) \\ Rodrigo de Sousa Melo (MELO, R. de S.) ${ }^{* *}$
}

\begin{abstract}
RESUMO - Este artigo analisou a relação entre resorts e desenvolvimento local na cidade de Ilha Grande (Piauí, Brasil), com ênfase na análise dos discursos dos representantes do setor público, do privado e da comunidade local. Como procedimentos metodológicos foram utilizados as pesquisas bibliográficas e de campo, com a aplicação de entrevistas estruturadas com os atores envolvidos, e para análise dos dados o método análise do discurso. Os resultados indicaram que o processo de discussão foi pautado por opiniões divergentes entre os diversos atores investigados. Os discursos foram caracterizados por uma combinação de argumentos técnicos e políticos para analisar a relação proposta. Observou-se também que os atores locais estavam pouco preparados para discutir um tema tão polêmico, pois muitos avaliaram e julgaram sem informações suficientes para tal, o que revelou um despreparo técnico e político para o processo de discussão.
\end{abstract}

Palavras-chave: Resorts; Desenvolvimento Local; Atores sociais.

ABSTRACT - The present article analyzed the relationship between resorts and local development in the city of Ilha Grande (Piauí State, Brazil), with emphasis on discourses analysis of the public and private sectors representatives and the local community. The methodological procedures employed were bibliographic and field research as well as structured interviews with the actors involved; and the data analysis method used was discourse analysis. The results indicated that the discussion process was marked by diverging opinions among the several actors investigated. The speeches were characterized by a combination of technical and political arguments to examine the relationship proposed. It was also observed that the local actors were poorly prepared to discuss such polemic theme, since many of them evaluated and judged themselves people without enough information about this matter, which revealed a lack of technical e political preparation to participate in the discussion process.

Key words: Resorts; Local development; Social actors.

\footnotetext{
* Graduação em Turismo (Bacharelado) pela Universidade Federal do Piauí - UFPI (Campus Parnaíba). Endereço: Av. São Sebastião, 2819. CEP: 64202-020 - Parnaíba - Piauí (Brasil). Telefone: (86) 99934586. E-mail: silvanyndasilva@yahoo.com.br

** Graduação em Turismo (Bacharelado) pela Universidade Católica de Pernambuco - UNICAP-PE. Mestrado em Desenvolvimento e Meio Ambiente (Programa de Pós-Graduação em Desenvolvimento e Meio Ambiente, PRODEMA - Universidade Federal da Paraíba, UFPB). Doutorando em Desenvolvimento e Meio Ambiente - UFPI. Professor Assistente do Curso de Graduação em Turismo (Bacharelado) da UFPI (Campus Parnaíba). Endereço: Av. Pinheiro de Machado, 770, ap. 211. CEP 64215-420, Parnaíba - Piauí (Brasil). Telefone: (86) 9976-0443. E-mail: rodrigomelotur@hotmail.com
} 


\section{INTRODUÇÃO}

Os resorts são empreendimentos de grande porte que ofertam além da hospedagem convencional, múltiplos serviços relacionados ao lazer, e dispõem de infraestrutura de grande porte para satisfazer o desejo dos hóspedes sem que estes precisem se deslocar para outros locais. A Organização Mundial de Turismo - OMT define resorts como "destinos turísticos integrados e relativamente independentes que oferecem uma variedade de instalações e atividades para os turistas" (OMT, 2001 apud SILVA; VIEIRA FILHO, 2009, p. 2) ${ }^{1}$.

Estes empreendimentos normalmente são instalados em locais com atrativos naturais, proporcionando ao hóspede maior convívio com a natureza, um dos principais motivadores de deslocamento da época contemporânea. Os resorts têm como característica sua localização, pois são instalados longe dos centros urbanos e geralmente próximos a praias, florestas e montanhas.

Os resorts também são conhecidos como complexos turísticos, visto que são planejados e destinados a uma demanda específica, neste caso, a de lazer (SILVA, 2004). Segundo Rosa e Tavares (2002 apud LOUREIRO, 2005, p. 50) $)^{2}$ : "Os resorts podem ser definidos como hotéis de lazer, situados fora dos centros urbanos, em locais com algum atrativo natural, e que sejam autocontidos”, ou auto-suficientes com serviços completos para o hóspede, estimulando-o a permanecer o máximo de tempo possível no empreendimento.

Estes complexos turísticos ocupam grandes áreas livres para comportar os equipamentos de lazer. De acordo com Silva (2004) entre estes equipamentos estão: campos de golfe, piscinas e quadras poliesportivas.

Com o crescimento da atividade turística e o aumento do número destes empreendimentos implantados, principalmente na região nordeste do Brasil, em função do clima tropical com predomínio de sol e calor durante mais da metade do ano, alguns gestores vêem neles uma maneira de trazer desenvolvimento para as cidades, beneficiando economicamente à população através da geração de emprego e renda.

\footnotetext{
${ }^{1}$ ORGANIZAÇÃO MUNDIAL DO TURISMO. Introdução ao turismo. Trad. de Dolores Martin Rodriguez Córner. São Paulo: Roca, 2001.

${ }^{2}$ ROSA, S. E. S. da; TAVARES, M. M. A recente expansão dos resorts no Brasil. BNDES Setorial, Rio de Janeiro, n. 16, p. 85-104, Set/2002.
} 
Uma questão relevante nesse contexto é a necessidade de buscar uma integração entre o poder público, a iniciativa privada e a comunidade local, evitando que o turismo se desenvolva de forma desordenada, com o aumento dos impactos sócioambientais negativos advindos da instalação de resorts. Outra questão relevante, no processo de desenvolvimento turístico de um destino, é que os atores sociais participem do planejamento, da implementação e da gestão da atividade turística.

Uma cidade ou estado não se torna em um destino turístico apenas por possuir atrativos turísticos, é necessário um processo em que os diferentes atores sociais estejam envolvidos no desenvolvimento do turismo na região, a fim de desenvolvê-la de forma sustentável. Embora não seja uma tarefa fácil, para alcançar o desenvolvimento sustentável da atividade turística em todas as suas dimensões é relevante a participação dos diversos atores sociais no planejamento e gestão do turismo. Segundo Ávila e Santos (2009, p. 5):

O alcance do equilíbrio adequado da participação dos diferentes setores envolvidos com o desenvolvimento do turismo não é tarefa das mais fáceis. Sabe-se que a atividade turística é extremamente ambígua, pois existe a necessidade de conciliar prática social e interesses econômicos, lazer com trabalho, e interesses de visitantes e anfitriões. Mediar estes elementos de forma adequada pode representar um desafio para aqueles que interferem no processo de desenvolvimento turístico.

Na busca do êxito no processo de desenvolvimento do turismo em um destino os atores sociais (poder público, iniciativa privada e comunidade local) precisam participar de todas as fases do planejamento à gestão, cientes de suas responsabilidades nesse processo. A inserção de uma comunidade local no processo de desenvolvimento turístico é relevante desde que esta esteja consciente, motivada e capacitada para participar do processo de planejamento do turismo. Por vezes, a partcipação se manifesta apenas representativamente e fisicamente, mas sem direito a voz e voto.

No processo de desenvolvimento turístico o poder público em suas esferas nacional, estadual e municipal tem como responsabilidades o planejamento e o incentivo a ações que desenvolvam de maneira responsável o turismo numa região, compatibilizando o uso turístico, com a conservação dos patrimônios natural e cultural, e com a melhoria da qualidade de vida da população local. Pois "o setor público beneficia-se da atividade de duas formas: indiretamente, através dos impostos que 
arrecada da empresa privada, e diretamente, pelas taxas que cobra dos turistas" (BARBOSA, 2005, p. 110).

O poder público tem como benefícios ainda:

Melhorar qualitativamente a vida da comunidade local, capacitar os recursos humanos, a preservação e conservação dos recursos naturais e culturais, geração de emprego, maior arrecadação de impostos dentre outros. (GÂNDARA et al. 2005, p. 35)

A iniciativa privada representa outro grupo de atores sociais importantes no processo de desenvolvimento turístico. O setor privado é composto pelos meios de hospedagem, agências de viagens, restaurantes, operadoras de turismo, organizadores de eventos e outros, e cabe a ele investir em infraestrutura e em serviços de qualidade para atender a uma demanda cada vez mais exigente. No que tange aos benefícios que a iniciativa privada pode obter, segundo Gândara et al. (2005, p. 35): “impactos econômicos e sociais positivos, mão de obra qualificada, dinamização econômica do setor, marca competitiva dentre outros". A comunidade local também possui suas responsabilidades no processo de desenvolvimento turístico da região, são eles:

A conservação dos recursos, a preservação do patrimônio, a participação ativa no processo de desenvolvimento, fomentar o desenvolvimento de novas obras de infra-estruturas e serviços, participar do controle do desenvolvimento atuando no planejamento e na gestão do mesmo, estimular a expansão de outras atividades econômicas, eleição de políticos e autoridades competentes, ser vigia da sua cidade, promover positivamente a sua cidade, atender bem aos visitantes, promover a limpeza e a ordem em geral, apropriar-se da identidade local, participar e cooperar nos programas desenvolvidos, facilitar aos turistas a compreensão da cidade, etc. (GÂNDARA et al., 2005, p. 36).

Ao envolver a comunidade local no processo de desenvolvimento do turismo é necessário que lhe seja oferecida benefícios tais como:

Prioridade da criação de emprego para os residentes nas empresas de turismo em desenvolvimento, assistência técnica e créditos empresariais locais para criar pequenas empresas de turismo, melhoria da infra-estrutura básica, atribuição de parte dos ganhos do turismo para a melhoria de instalações e serviços gerais da comunidade, organização dos artesãos para produzir e vender seus artigos aos turistas, estimular atividades culturais como a dança, a música ou o teatro, preservando a autenticidade das tradições locais e desenvolver programas de uso de produtos locais. (OMT, 1999 apud ÁVILA; SANTOS, 2009, p. 9). 
A união de todos esses atores sociais no processo de desenvolvimento turístico de um destino pode contribuir para a evolução social, econômica e política de todos os envolvidos, garantindo, com isso, a repartição dos benefícios gerados e a minimização dos possíveis impactos sociais, econômicos e ambientais. Para melhor entendimento e clareza julgou-se ser pertinente demonstrar as abordagens de diversos autores (SILVA e VIEIRA FILHO, 2009; INSKEEP e KALLENBERGER, 1991; LOUREIRO, 2005; BARROS, 1999 e CORIOLANO, 2009) que analisam a questão da implantação de resorts e os vêem como uma forma positiva ou negativa de desenvolvimento turístico. Essas abordagens são apresentadas no Quadro 1.

\begin{tabular}{|c|c|}
\hline ABORDAGENS POSITIVAS & ABORDAGENS NEGATIVAS \\
\hline $\begin{array}{l}\text { Vale lembrar que o crescimento dos resorts no } \\
\text { Brasil favorece a competitividade do produto } \\
\text { turístico brasileiro no exterior, uma vez que tais } \\
\text { empreendimentos são comumente tidos como uma } \\
\text { maneira viável de países em desenvolvimento } \\
\text { incrementarem a atividade turística e a entrada de } \\
\text { divisas em seus territórios. (SILVA; VIEIRA } \\
\text { FILHO, 2009, p. 2). }\end{array}$ & $\begin{array}{l}\text { Os resorts muitas vezes se encontram } \\
\text { desvinculados do entorno e da comunidade, não } \\
\text { geram renda nem emprego, não valorizam a cultura } \\
\text { local como um atrativo turístico ou contribuem de } \\
\text { alguma forma para a melhoria da qualidade de vida } \\
\text { da população local. (SILVA; VIEIRA FILHO, } \\
\text { 2009, p. 5). }\end{array}$ \\
\hline $\begin{array}{l}\text { Os resorts normalmente beneficiam } \\
\text { economicamente a região onde estão inseridos na } \\
\text { medida em que pagam impostos, geram empregos e } \\
\text { contribuem para o equilíbrio da balança de } \\
\text { pagamentos. (SILVA; VIEIRA FILHO, 2009, p. 2). }\end{array}$ & $\begin{array}{l}\text { Se por um lado os moradores locais podem ser } \\
\text { utilizados como mão de obra, por outro o acesso } \\
\text { deles às instalações do resort costuma ser inviável, } \\
\text { dados os altos prescos praticados no } \\
\text { empreendimento. (SILVA; VIEIRA FILHO, 2009, } \\
\text { p. 5). }\end{array}$ \\
\hline $\begin{array}{l}\text { Um resort bem planejado, desenvolvido e } \\
\text { administrado tem tudo para ser bastante rentável e } \\
\text { trazer diversos e importantes benefícios } \\
\text { econômicos e sociais para a região na qual está } \\
\text { inserido. (INSKEEP; KALLENBERGER, } 1991 \\
\text { apud LOUREIRO, 2005, p. 54). }\end{array}$ & $\begin{array}{l}\text { É importante lembrar que não é somente a } \\
\text { construção do resort em si que afeta a natureza. } \\
\text { Existe toda uma infraestrutura por trás, que se faz } \\
\text { necessária para o funcionamento do mesmo. } \\
\text { (LOUREIRO, 2005, p. 92). }\end{array}$ \\
\hline $\begin{array}{l}\text { O Resort é um bom exemplo de que a convivência } \\
\text { harmoniosa do homem com a natureza não só é } \\
\text { possível, mas também rentável. (BARROS, 1999, } \\
\text { p. 38). }\end{array}$ & $\begin{array}{l}\text { Se os grandes hotéis e os resorts simbolizam } \\
\text { acumulação e concentração de capital no setor } \\
\text { turístico, as pousadas ou os pequenos hotéis podem } \\
\text { simbolizar novas imagens de um turismo menos } \\
\text { concentrador e mais solidário, menos pasteurizado } \\
\text { e mais atento à diversidade cultural. } \\
\text { (CORIOLANO, 2009, p. 280). }\end{array}$ \\
\hline
\end{tabular}

QUADRO 1 - DIFERENTES ABORDAGENS SOBRE EMPREENDIMENTOS DE GRANDE PORTE (RESORTS) SEGUNDO VÁRIOS AUTORES.

FONTE: SILVANY SILVA, 2010. 
Na cidade de Ilha Grande, litoral do estado do Piauí (PI), região nordeste do Brasil, uma das ilhas integrantes da região do Delta do Parnaíba, recentemente houve a possibilidade de implantação de um complexo turístico chamado "Projeto Ecocity Brasil (Resort)", o qual gerou bastante polêmica entre os representantes do poder público, da iniciativa privada e da comunidade local. O empreendimento seria implantado numa área total de 80 milhões de metros quadrados ao longo de 30 anos (JR PROJECT MANAGEMENT, 2009).

Desta forma, este artigo objetivou analisar os discursos dos representantes do poder público, da iniciativa privada e da comunidade local sobre a implantação de resorts na cidade de Ilha Grande (Piauí, Brasil), pois considerou-se que estes empreendimentos estão sendo discutidos e implantados no Brasil sem que haja um entendimento sobre a preparação dos atores locais para discutir e analisar conceitual e tecnicamente os aspectos positivos e negativos referentes aos projetos propostos.

\section{CARACTERIZAÇÃO DO PROJETO ECOCITY BRASIL}

O "Projeto Ecocity Brasil" recentemente discutido, foi concebido e proposto pela World Ecologic Center Projetos Turísticos e Ecológicos (JR PROJECT MANAGEMENT, 2008), sua localização e outras características são apresentadas na Figura 1.

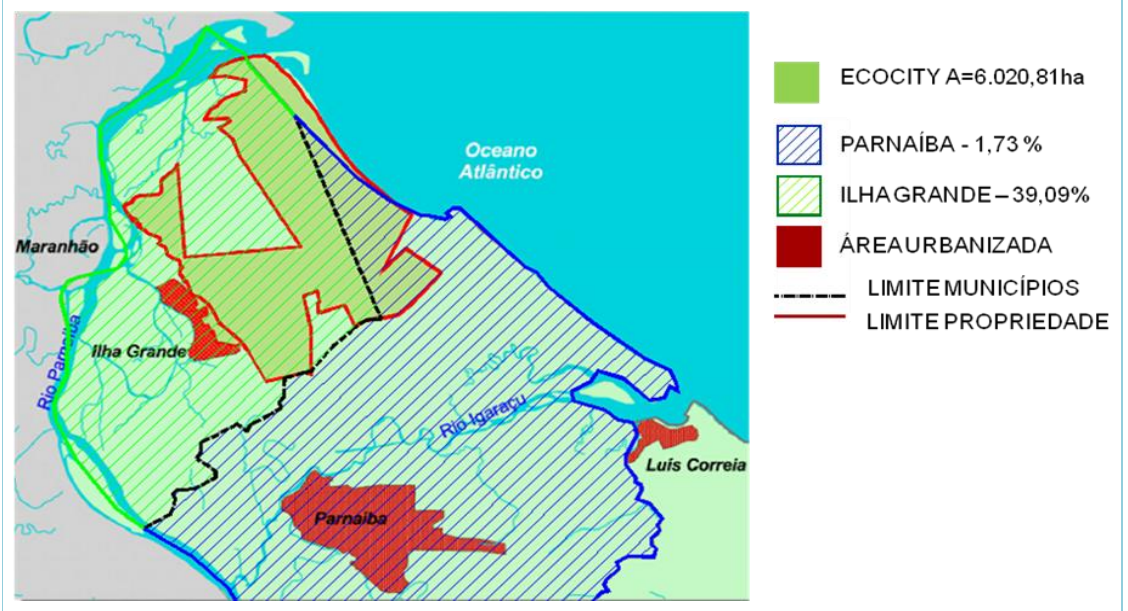

FIGURA 1 - LOCALIZAÇÃO DO EMPREENDIMENTO PROJETO ECOCITY BRASIL. FONTE: JR PROJECT MANAGEMENT (2008). 
O projeto estipulava como objetivo geral, segundo seus autores, a implantação no litoral do Estado do Piauí de um complexo turístico especial, norteada pelo princípio da sustentabilidade, que elevaria a cidade de Ilha Grande à condição de "Capital Mundial do Meio Ambiente".

De acordo com o projeto, sua concepção seria dependente da conservação da natureza e da preservação do meio ambiente, uma vez que seriam utilizadas medidas mitigadoras e preventivas para minimizar os impactos causados pelo empreendimento. O projeto era composto de cinco etapas e cada qual com duração de 6 anos, ou seja, sua implantação total seria em 30 anos.

O projeto desenvolveria programas de inserção social, como o treinamento de pessoal, a melhoria das condições de habitação da população residente, a implantação de uma ZEIS (Zona Especial de Interesse Social), e a criação de programas de valorização da cultura local. No aspecto ambiental, seriam desenvolvidos programa de gestão ambiental, de pesquisa e desenvolvimento, com a utilização de energias renováveis e a reciclagem de materiais.

De acordo com o exposto pelos autores do projeto, ele contemplaria a valorização da cultura local e a parceria com o setor público, com entidades representativas da sociedade e com a população local. Além disso, seguiria também os princípios do urbanismo bio-climático, ecológico e sustentável. Com relação ao meio ambiente o projeto iria aliar-se a todas as iniciativas preservacionistas e no desenvolvimento de projetos de recuperação ambiental.

De acordo com o último Estudo de Impacto Ambiental - EIA e Relatório de Impacto Ambiental - RIMA (JR PROJECT MANAGEMENT, 2008) indeferido pelo IBAMA (Instituto Brasileiro do Meio Ambiente e dos Recursos Naturais Renováveis), os impactos negativos estão voltados ao meio físico e biológico na área de inserção do empreendimento. $\mathrm{E}$ os impactos positivos estão vinculados aos meios sociais e econômicos, com a perspectiva de melhoria da infraestrutura local, contribuindo para a geração de emprego e renda para a população local.

O estudo concluiu a partir dos aspectos ambientais diagnosticados que, segundo seus idealizadores, o empreendimento possuía bases técnicas para sua implantação e funcionamento dentro do paradigma da sustentabilidade, o que contribuiria para o 
reconhecimento da cidade de Ilha Grande como capital mundial do meio ambiente (JR PROJECT MANAGEMENT, 2008).

Após uma série de discussões e polêmicas o projeto foi embargado pelo IBAMA, o qual solicitou vários ajustes e modificações para adequação do projeto às condições ambientais e sociais da cidade de Ilha Grande.

\section{METODOLOGIA}

Quanto aos fins, a presente pesquisa é tanto exploratória, pois segundo Severino (2007), teve como objetivo o levantamento de informações sobre um determinado objeto, conformando desta forma um campo de estudo, e mapeando as características do objeto investigado. Quanto descritiva na medida em que objetivou descrever e analisar os discursos dos atores do setor público, da iniciativa privada e da comunidade local sobre o processo de discussão da implantação de resorts na cidade de Ilha Grande.

A pesquisa baseou-se em uma abordagem qualitativa, dentre os meios utilizados para a construção do estudo utilizou-se a pesquisa bibliográfica que deu suporte ao embasamento teórico-conceitual com informações relevantes relacionadas com o tema proposto.

Além de balizar o desenvolvimento da investigação, tal pesquisa serviu também para dar cientificidade ao trabalho, Pádua (2004) afirma que a finalidade da pesquisa bibliográfica é localizar o que já foi produzido e registrado sobre um determinado tema.

Outro meio utilizado foi o da pesquisa de campo realizada para a obtenção de dados primários. Segundo Lakatos e Marconi (2006) a pesquisa de campo baseia-se na observação de fenômenos ou fatos referentes a um dado objeto de estudo.

Como instrumento de pesquisa, utilizou-se as entrevistas, para Lakatos e Marconi (2006) tal instrumento se operacionaliza quando ocorre o encontro de duas pessoas, de forma que uma delas obtém da outra, informações e dados referentes ao objeto estudado.

As entrevistas foram do tipo estruturadas, que são aquelas construídas previamente, e compostas de perguntas direcionadas a um público específico 
(SEVERINO, 2007). Foram aplicadas aos representantes do setor privado, da iniciativa privada e da comunidade local.

Os sujeitos da pesquisa corresponderam aos representantes do setor público: 1 (um) representante da Secretaria de Turismo e Meio Ambiente da cidade de Ilha Grande; 1 (um) representante do Instituto Chico Mendes (ICMBio); 1 (um) representante do IBAMA; do setor privado: 3 (três) representantes de Agências de viagens; e 20 (vinte) moradores das comunidades locais. Totalizando assim uma amostra de 26 (vinte e seis) entrevistados.

Após a aplicação das entrevistas, as informações foram analisadas com base no método análise do discurso (CORIOLANO, 2005), verificando o posicionamento dos discursos dos atores sociais entrevistados sobre o tema investigado.

De acordo com Coriolano (2005, p. 51),

É uma metodologia voltada especialmente à análise qualitativa e baseada nos princípios da concepção múltipla da realidade, que busca as relações e correlações, que interroga sobre a intencionalidade das ações e leva a uma pesquisa participativa e participante, apreende mais a realidade e aproxima-se mais do real.

Este método permite o conhecimento dos saberes produzidos pelas sociedades sobre determinada temática. O discurso não é algo absoluto, visto que nasce a partir de outros discursos e deles sofrem interferência.

Na sociedade convivem múltiplos discursos e segundo Coriolano (2005, p. 51) "as instituições caracterizam-se por discursos. O turismo tem um discurso próprio." Esses discursos são formulados pelos governos, representantes da iniciativa privada e pela comunidade. Os discursos possuem significados distintos para os atores sociais, pois com relação ao turismo, para uns o turismo é tido como degradador e para outros como um meio de desenvolvimento. Segundo a autora:

Os discursos e as práticas políticas dos governos e dos grandes empresários diferem dos discursos das comunidades e dos pequenos empreendedores, porque tem focos de interesse específicos. (CORIOLANO, 2005, p. 54). 


\section{RESULTADOS E DISCUSSÃO}

Com relação ao conhecimento do "Projeto Ecocity Brasil", no Gráfico 1 se destaca que a maioria dos respondentes afirmaram conhecê-lo (16 pessoas), já 6 deles alegaram ter pouco conhecimento e 4 declararam não ter conhecimento do projeto.

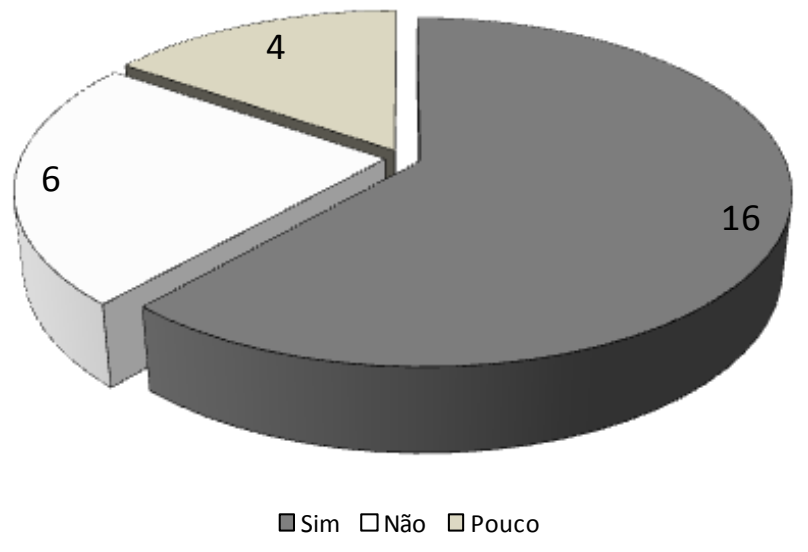

GRÁFICO 1 - CONHECIMENTO DO PROJETO ECOCITY BRASIL FONTE: SILVANY SILVA, 2010.

O Gráfico 2 demonstra que a maioria dos entrevistados (14 pessoas) tomou conhecimento do projeto através de conversas informais, outros souberam por meio de participação em audiência pública (5 pessoas), meios de comunicação (4 pessoas), e alguns não possuíam conhecimento do projeto (3 pessoas).

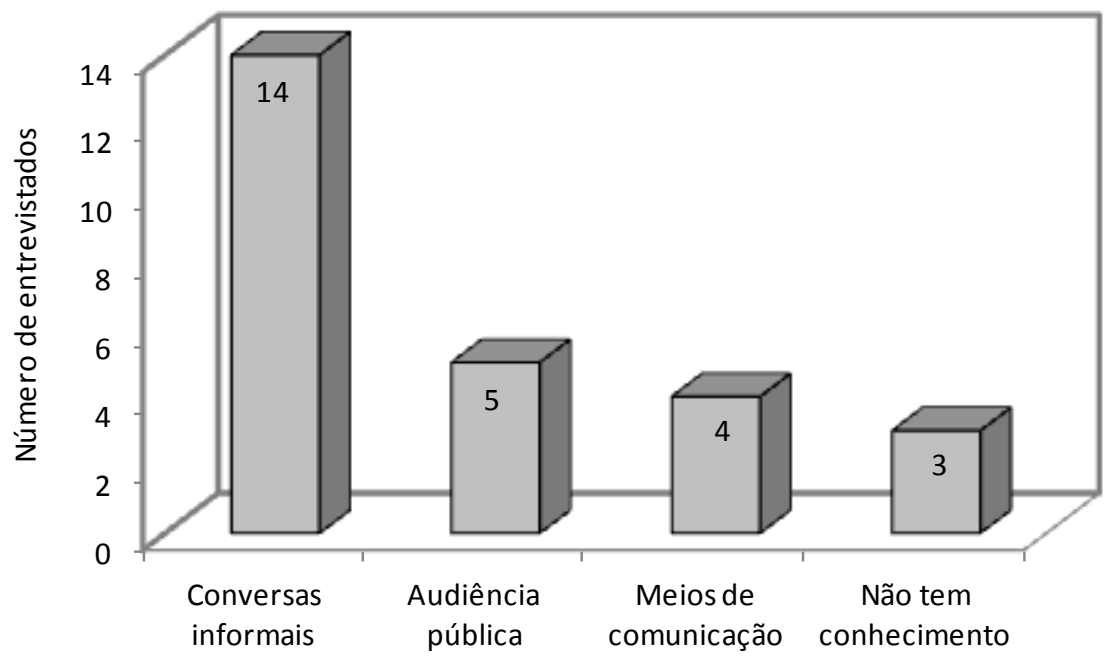

GRÁFICO 2 - COMO TOMOU CONHECIMENTO DO PROJETO ECOCITY BRASIL? FONTE: SILVANY SILVA, 2010. 
Cabe destacar que apesar de ter ocorrido uma audiência pública sobre o empreendimento na Câmara Municipal de Ilha Grande (PI), poucas pessoas souberam ou tiveram interesse em participar. Como apresenta o referido gráfico, 14 dos entrevistados tomaram conhecimento do projeto por meio de conversas informais, e é importante ressaltar que geralmente nessas conversas as informações são repassadas de forma distorcida e influenciadas pelas ideologias políticas e pessoais de quem as transmitem.

O diálogo entre o setor público e o privado ocorreu entre as entidades como o IBAMA, o ICMBIO, a Secretaria de Turismo e Meio Ambiente da cidade de Ilha Grande e a empresa responsável pelo empreendimento. Sobre os benefícios que o empreendimento traria para a cidade, o Quadro 2 apresenta os discursos mais relevantes dos atores sociais entrevistados.

\begin{tabular}{|c|l|}
\hline BENEFÍCIOS & \multicolumn{1}{|c|}{ DISCURSOS } \\
\hline Benefícios sociais & "Organização de capital social". (Representante da comunidade) \\
\hline Benefícios ambientais & $\begin{array}{l}\text { "Segundo eles, a preservação do meio ambiente através do uso do } \\
\text { desenvolvimento sustentável". (Representante da comunidade) }\end{array}$ \\
\hline Benefícios econômicos & $\begin{array}{l}\text { "Emprego". (Representante da iniciativa privada) } \\
\text { "O empreendimento poderia movimentar a economia local, no } \\
\text { momento de sua construção e depois com o seu funcionamento, } \\
\text { gerando tributos que poderiam melhorar as finanças públicas". } \\
\text { (Representante do poder público) }\end{array}$ \\
\hline Outros benefícios & $\begin{array}{l}\text { "Divulgação da região". (Representante da iniciativa privada) } \\
\text { "Trazer o turismo para a região". (Representante do setor público) }\end{array}$ \\
\hline Não traria benefícios & $\begin{array}{l}\text { "Crescer mais a infraestrutura e abrir caminhos para o turismo". } \\
\text { (Representante da iniciativa privada) }\end{array}$ \\
\hline "Nepresentante da iniciativa privada) \\
\hline
\end{tabular}

QUADRO 2 - BENEFÍCIOS DO EMPREENDIMENTO PARA A CIDADE

FONTE: SILVANY SILVA, 2010.

Neste questionamento, os benefícios econômicos foram os mais destacados, principalmente pelos atores do setor público. Do setor privado apenas um disse que o 
empreendimento não traria benefícios. Vale destacar que apenas um representante da comunidade enfatizou sobre os benefícios ambientais do empreendimento. Alguns entrevistados destacaram outros benefícios como a divulgação e o crescimento do turismo.

Observou-se a existência de entrevistados que não identificaram benefícios para a cidade com a implantação do projeto. Destaca-se também o discurso de um representante da comunidade que apresentou como benefício à organização de capital social, pois segundo ele com a implantação do empreendimento as associações existentes no município poderiam se motivar e se engajar no processo de desenvolvimento do turismo em Ilha Grande. Ressalta-se também o discurso de um representante da iniciativa privada que mencionou acreditar que o empreendimento traria como benefício o crescimento da infraestrutura da cidade.

Com relação aos malefícios que o empreendimento traria para a cidade, os discursos apresentados pelos atores sociais entrevistados estão dispostos no Quadro 3, enquadrados nas categorias sociais, ambientais e econômicas.

\begin{tabular}{|c|l|}
\hline MALEFÍCIOS & \multicolumn{1}{|c|}{ DISCURSOS } \\
\hline Malefícios sociais & $\begin{array}{l}\text { "Descaracterização do lugar, choque de culturas e praias privadas". } \\
\text { (Representante da iniciativa privada). } \\
\text { "Desapropiação de famílias no local da área ocupada". (Representante } \\
\text { da comunidade). } \\
\text { "Poderia atrair pessoas ou problemas relacionados à prostituição e } \\
\text { drogas". (Representante da comunidade). }\end{array}$ \\
\hline Malefícios ambientais & $\begin{array}{l}\text { "A dimensão do empreendimento é outra preocupação, ainda que } \\
\text { projetado para ser implantado até 2030, se não me engano. A estimativa } \\
\text { é de 96.000 leitos, uma projeção ultra-mega-hiper faraônica, para uma } \\
\text { região reconhecida pelas fragilidades ambientais existentes". } \\
\text { (Representante do setor público). }\end{array}$ \\
\hline MONTE: SILVANY SILVA, 2010. \\
$\begin{array}{l}\text { "Turismo de massa que pode trazer impacto ambiental". (Representante } \\
\text { do setor público). }\end{array}$ \\
\hline Malefícios econômicos & $\begin{array}{l}\text { "Ninguém da comunidade teria emprego, somente nos estágios iniciais". } \\
\text { (Representante da comunidade). }\end{array}$ \\
\hline
\end{tabular}


Com relação aos malefícios, os mais destacados pelos entrevistados foram os de cunho ambiental, e os representantes da comunidade local enfatizaram como principal malefício a desapropriação dos moradores de suas terras, fato este atualmente observável em várias regiões do país.

O Gráfico 3 apresenta quem seriam os beneficiados, segundo os atores locais entrevistados, com a implantação do projeto Ecocity Brasil.

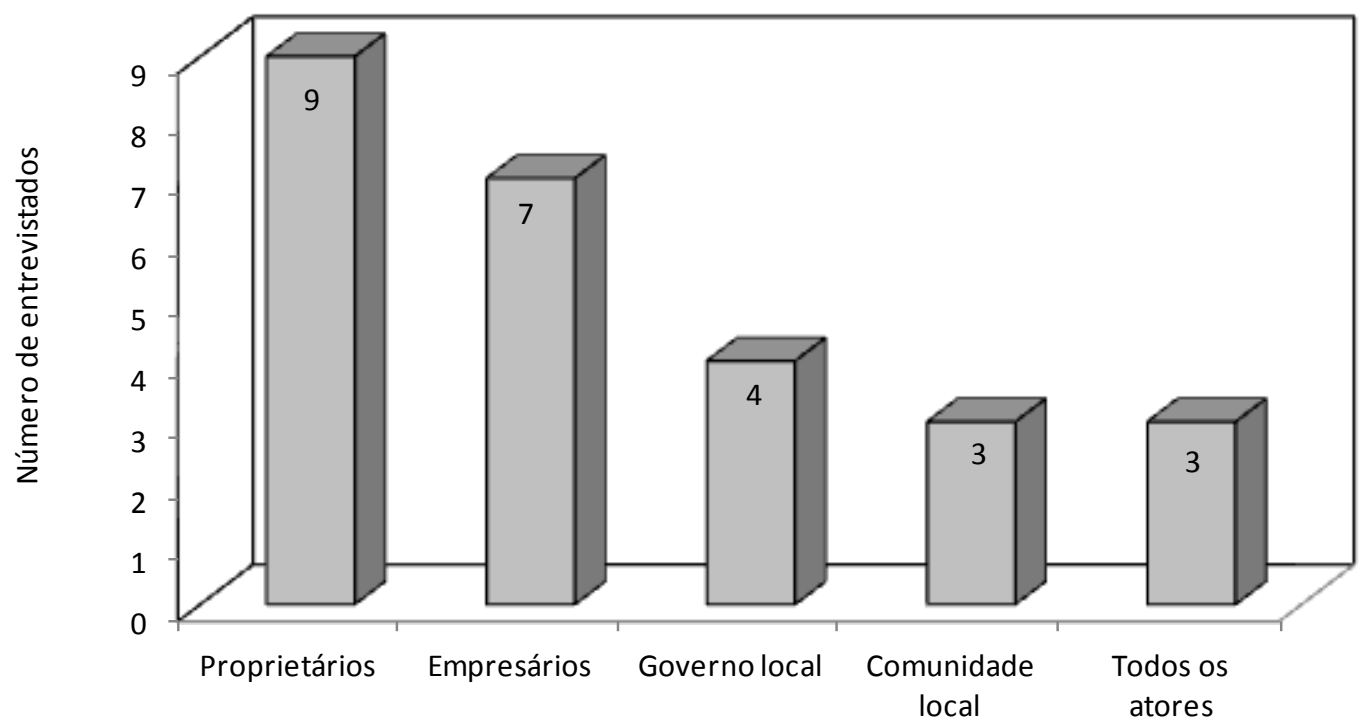

GRÁFICO 3 - QUEM SERIAM OS BENEFICIADOS COM A IMPLANTAÇÃO DO PROJETO? FONTE: SILVANY SILVA, 2010.

Perguntados sobre os possíveis beneficiados com a implantação do empreendimento uma parcela significativa (9 pessoas) apontou os próprios proprietários como os maiores beneficiados, seguido dos empresários com 7 citações.

Alguns mencionaram acreditar que o governo local seria o maior beneficiado com a implantação do projeto (4 pessoas), e empatados com 3 respondentes, a comunidade local e todos os atores sociais seriam os maiores beneficiados. Concluiu-se haver certo pessimismo por parte da maioria dos entrevistados quanto aos benefícios do empreendimento para a população local.

Com relação à avaliação por parte dos atores sociais entrevistados sobre o processo de discussão do projeto, os discursos mais relevantes são apresentados no Quadro 4. 


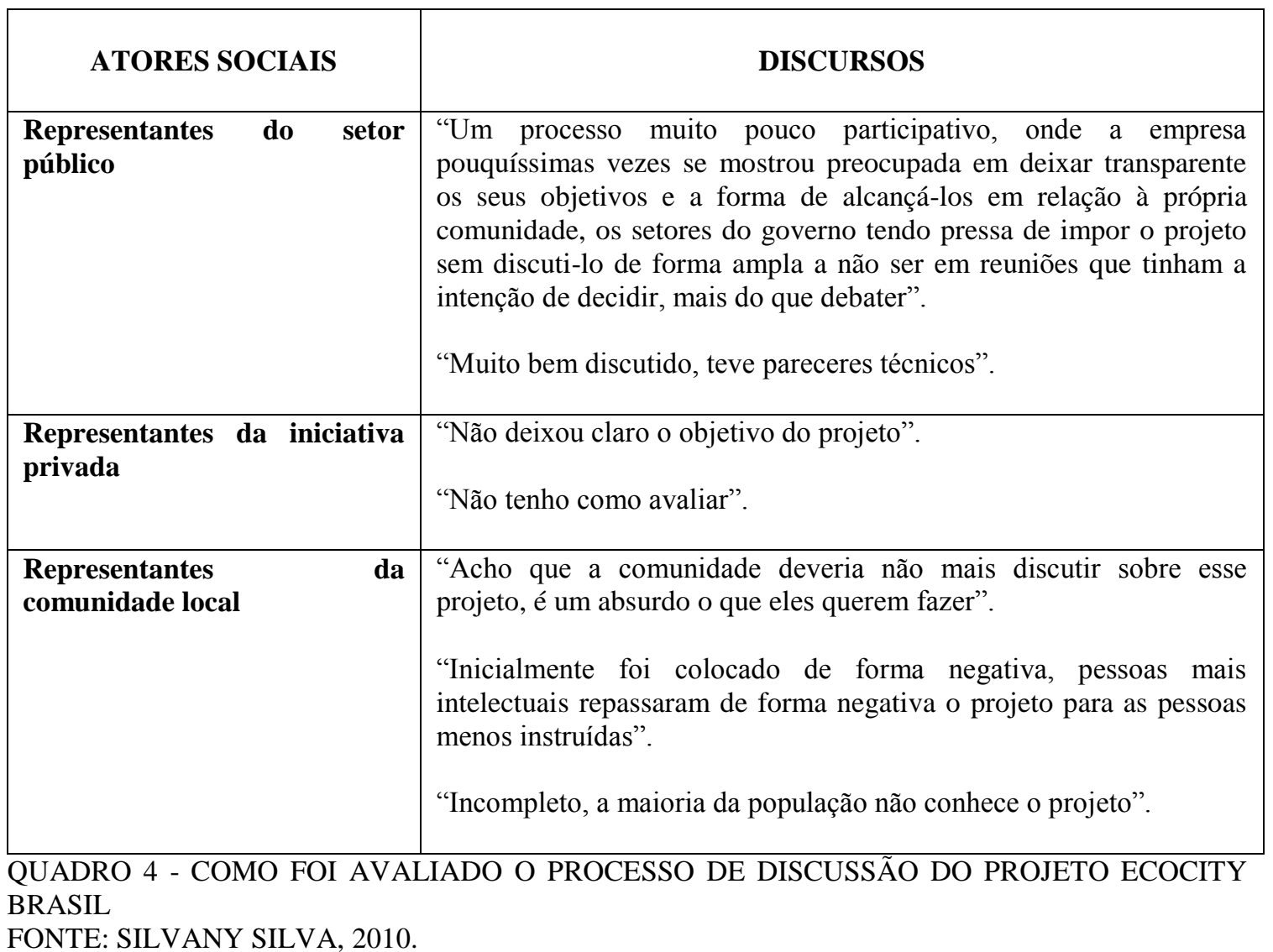

Neste questionamento percebeu-se através dos discursos dos entrevistados que o projeto foi exposto, porém que não foi um processo participativo. Apesar das audiências públicas realizadas, os representantes da comunidade local não tiveram grande presença, isso se confirma nos resultados apresentados no Gráfico 2, pois grande parte deles tomaram conhecimento do projeto através de conversas informais. Cabe destacar o discurso de um representante da comunidade, o qual proferiu que pessoas da comunidade com um grau de conhecimento mais elevado influenciaram as pessoas menos instruídas quanto à percepção do empreendimento no município. Para alguns entrevistados a empresa não deixou claro quais eram seus objetivos, pois segundo eles, em cada reunião o projeto era apresentado de forma diferente.

Quando perguntado se os atores locais possuíam informações suficientes para avaliar o projeto, o Gráfico 4 demonstra que a grande maioria dos entrevistados disse que não (17 pessoas), apenas 7 afirmaram que tinham informações suficientes para avaliá-lo e 2 deles disseram que tinham informações parciais para avaliar o projeto. 


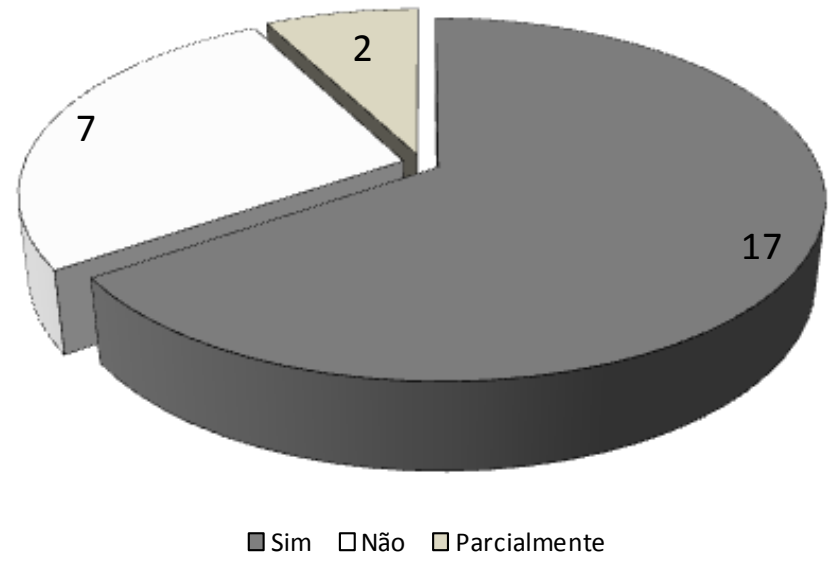

GRÁFICO 4 - INFORMAÇÕES SUFICIENTES PARA AVALIAR O PROJETO.

FONTE: SILVANY SILVA, 2010.

Apesar da grande parcela dos entrevistados afirmarem ter conhecimento do projeto, eles não demonstraram possuir informações suficientes para avaliá-lo, isso supostamente se deve ao fato de que muitos só ficaram sabendo do projeto através de conversas informais e sem informações oficiais. O Quadro 5 apresenta os discursos dos atores sociais entrevistados quanto aos objetivos do projeto e sua comparação com as informações oficiais fornecidas pelos empreendedores.

\begin{tabular}{|c|c|c|}
\hline ATORES SOCIAIS & DISCURSOS & $\begin{array}{l}\text { INFORMAÇÕES } \\
\text { OFICIAIS }\end{array}$ \\
\hline $\begin{array}{l}\text { Representantes do setor } \\
\text { público }\end{array}$ & $\begin{array}{l}\text { "A argumentação do governo era no sentido de } \\
\text { trazer melhorias na qualidade de vida dos } \\
\text { moradores de Ilha Grande e de dinamizar a } \\
\text { atividade turística no município e estado". } \\
\text { "Montar uma grande estrutura para atrair o } \\
\text { turista com a finalidade de gerar renda". }\end{array}$ & \multirow{3}{*}{$\begin{array}{l}\text { O projeto apresenta } \\
\text { como objetivo a } \\
\text { implantação no litoral } \\
\text { do Estado do Piauí de } \\
\text { um complexo turístico } \\
\text { especial, norteada pelo } \\
\text { princípio da } \\
\text { sustentabilidade, que } \\
\text { poderá elevar a cidade } \\
\text { de Ilha Grande à } \\
\text { condição de Capital } \\
\text { Mundial do Meio } \\
\text { Ambiente. }\end{array}$} \\
\hline $\begin{array}{l}\text { Representantes } \\
\text { iniciativa privada }\end{array}$ & $\begin{array}{l}\text { "Atender o público europeu”. } \\
\text { "Construção dos resorts e geração de emprego e } \\
\text { renda". }\end{array}$ & \\
\hline $\begin{array}{l}\text { Representantes } \\
\text { comunidade local }\end{array}$ & $\begin{array}{l}\text { "Implantação de uma grande cidade turística no } \\
\text { município". } \\
\text { "Fazer campos de golfes e resorts ecológicos". } \\
\text { "Ser reconhecido mundialmente". }\end{array}$ & \\
\hline
\end{tabular}

QUADRO 5 - QUAIS OS OBJETIVOS DO PROJETO?

FONTE: SILVANY SILVA, 2010. 
No que tange aos objetivos do projeto, os entrevistados se aproximaram do seu real objetivo, mesmo as pessoas que possuíam apenas informações superficiais. Alguns atores destacaram que o objetivo do projeto era a geração de emprego e renda e a melhoria da qualidade de vida dos moradores da cidade de Ilha Grande.

Quanto aos impactos sociais e ambientais que o projeto causaria na região, o Quadro 6 apresenta os discursos dos atores entrevistados.

\begin{tabular}{|c|c|}
\hline ATORES SOCIAIS & DISCURSOS \\
\hline Representantes do setor público & $\begin{array}{l}\text { "Ambientalmente não sei te falar, pois desconheço o motivo de } \\
\text { não ser implantado". } \\
\text { "Degradação ambiental, já que grande parte do projeto seria } \\
\text { implantado em áreas de dunas semifixas e restingas que no } \\
\text { inverno estão inundáveis". }\end{array}$ \\
\hline $\begin{array}{l}\text { Representantes da } \\
\text { privada }\end{array}$ & $\begin{array}{l}\text { "Choque cultural, não procura a integração com a comunidade". } \\
\text { "Desmatamento". }\end{array}$ \\
\hline $\begin{array}{l}\text { Representantes da comunidade } \\
\text { local }\end{array}$ & $\begin{array}{l}\text { "Perda da identidade cultural e degradação do meio ambiente". } \\
\text { "Os impactos sociais só iam ser percebidos com o tempo". } \\
\text { "Devastação da paisagem e pouco acesso da comunidade ao } \\
\text { empreendimento". }\end{array}$ \\
\hline
\end{tabular}

Percebeu-se que todos os atores entrevistados destacaram mais os impactos ambientais. Em virtude disso, é importante ressaltar que a atividade turística seja planejada e baseada nas dimensões da sustentabilidade e com a participação de todos os atores sociais no processo de planejamento e gestão da atividade. É relevante destacar que o turismo não deve ser considerado uma atividade negativa, pois com planejamento e engajamento dos atores envolvidos, ele pode se configurar numa alternativa de geração de emprego e renda para a população de um determinado local. Com relação aos impactos sociais, os entrevistados não souberam responder, alguns confundiram com impactos culturais, e destacaram o choque de culturas e a perda da identidade cultural como possíveis impactos. 
O Gráfico 5 mostra a opinião dos entrevistados com relação ao processo de discussão sobre o projeto, se foi pautado por argumentos técnicos e/ou políticos.

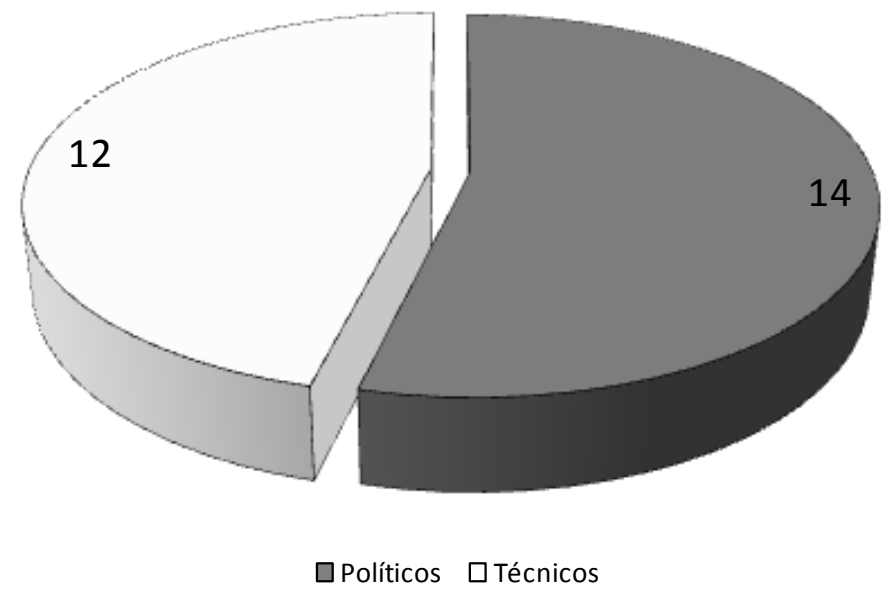

GRÁFICO 5 - A DISCUSSÃO FOI PAUTADA EM ARGUMENTOS TÉCNICOS OU POLÍTICOS? FONTE: SILVANY SILVA, 2010.

O número de citações referentes aos argumentos políticos foram 14 contra 12 dos argumentos técnicos. Portanto, segundo os entrevistados, considerou-se que a discussão sobre o projeto foi pautada tanto em argumentos técnicos quanto políticos. $\mathrm{O}$ Quadro 7 traz os discursos dos atores sociais referentes aos argumentos utilizados no processo de discussão.

\begin{tabular}{|l|l|}
\hline \multicolumn{1}{|c|}{ ATORES SOCIAIS } & \multicolumn{1}{|c|}{ DISCURSOS } \\
\hline Representantes do setor público & $\begin{array}{l}\text { "Acho que foi pautada por interesses econômicos e políticos, } \\
\text { muito mais do que por argumentos técnicos". }\end{array}$ \\
\hline Representantes da iniciativa privada & $\begin{array}{l}\text { "Não fiquei sabendo, não sei se foi feito demonstração mas } \\
\text { vejo que tem políticos envolvidos". }\end{array}$ \\
\hline Representantes da comunidade local & $\begin{array}{l}\text { "Político". } \\
\text { "Estudos técnicos, houve a participação de biólogos, } \\
\text { ambientalistas". } \\
\text { "Técnica, porém na comunidade foi política". } \\
\text { "Os dois tanto políticos quanto técnicos". }\end{array}$ \\
\hline QUADRO 7 - A DISCUSSÃO SOBRE O PROJETO FOI PAUTADA EM ARGUMENTOS TÉCNICOS \\
OU POLÍTICOS? \\
FONTE: SILVANY SILVA, 2010.
\end{tabular}


Observou-se que na maioria das respostas destacaram-se os dois argumentos, tanto políticos quanto técnicos. Nos discursos da comunidade poucos afirmaram que a discussão foi pautada apenas em argumentos técnicos. No que tange aos representantes do setor público, um discurso destacou-se, pois o entrevistado afirmou que além do interesse político havia o econômico.

Devido à pequena diferença quantitativa entre os argumentos, pode-se concluir que no processo de discussão do projeto houve argumentos tanto políticos quanto técnicos. Os argumentos técnicos referem-se aos estudos sobre o projeto e a elaboração do Estudo de Impacto Ambiental - EIA e Relatório de Impacto Ambiental - RIMA, e os argumentos políticos estão relacionados aos interesses e percepções dos atores locais sobre a implantação do projeto. O Gráfico 6 apresenta a percepção dos atores sociais se houvesse uma nova discussão do projeto.

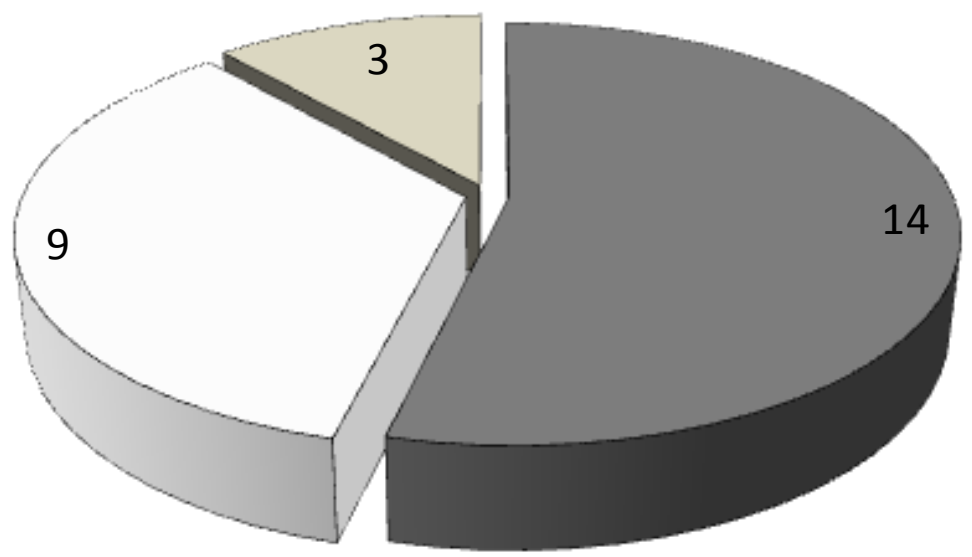

$\square$ Depende do novo projeto $\square$ Posição Contrária $\square$ Posição Favorável

GRÁFICO 6 - PERCEPÇÃO QUANTO A UMA NOVA DISCUSSÃO

FONTE: SILVANY SILVA, 2010.

Com relação a uma nova discussão a maioria dos respondentes (14 pessoas) destacou que dependeria do novo projeto, que procurariam se inteirar mais. Outros (9 pessoas) enfatizaram que manteriam-se contrários a implantação do projeto e 3 pessoas seriam favoravéis à implantação do projeto. Pelas respostas obtidas, observou-se que talvez a abordagem dos empreendedores não foi a mais cabível, e que torna-se difícil mudar o discurso daqueles que já tem uma opinião formada sobre um determinado assunto. 
Ressalta-se que o setor privado sozinho não desenvolve o turismo em uma localidade, sendo importante a parceria entre o poder público, a iniciativa privada e a comunidade local para que a atividade turística seja planejada e executada com eficácia para todos.

\section{CONSIDERAÇÕES FINAIS}

O turismo é uma atividade crescente no mundo atual e juntamente com ele surgem os resorts e também a valorização dos recursos naturais e culturais. A implantação destes empreendimentos gera conflitos entre os atores sociais que possuem percepções diferentes quanto ao desenvolvimento de um destino, portanto evidencia-se a importância da participação de todos os atores no processo de planejamento turístico de uma localidade.

Com relação ao projeto Ecocity Brasil observou-se que a forma de apresentação e discussão do projeto não foi a mais adequada e "assustou" de certa forma aqueles envolvidos no processo.

Para o governo local o empreendimento era um meio de geração de emprego e renda para a população e para a comunidade algo que viria a destruir os recursos ambientais já fragilizados pelas atividades econômicas realizadas no local e ainda expropriá-los de suas terras.

Na cidade de Ilha Grande o turismo não é uma atividade de destaque, a cidade não dispõe de infraestrutura turística e sua economia é baseada na agricultura, pecuária e serviços públicos. Analisando a cidade sem o empreendimento chega-se a conclusão que devido a fragilidade do ecossistema e com as atividades que têm acontecido no local como a retirada do mangue para dar lugar a plantações de arroz e a derrubada das árvores para fazer o carvão vegetal, as perspectivas não são animadoras.

Toda atividade turística causa impactos ao seu entorno, cabe aos atores sociais planejarem o turismo a fim de promover o desenvolvimento sustentável local nos seus aspectos sociais, ambientais, culturais e econômicos. O turismo não pode ser visto como um vilão, pois toda atividade planejada e administrada de forma efizaz pode trazer diversos benefícios. 
Sobre o processo de implantação do empreendimento concluiu-se que se houvesse uma nova discussão os atores sociais entrevistados procurariam se inteirar mais a fim de conhecer melhor o projeto. É importante ressaltar que Ilha Grande carece de investimentos e que se faz necessário existir parcerias entre o setor público e privado a fim de contribuir para o desenvolvimento econômico do município.

A participação de todos os atores sociais no processo de planejamento turístico contribuiria para a valorização do patrimônio cultural e ambiental, além de potencializar o uso sustentável dos recursos disponíveis no local, e minimizar os impactos negativos da atividade.

Os discursos são construções humanas e organizadas sobre um determinado tema e foi através dos dircursos dos atores públicos, privados e comunitários que se chegou a conclusão sobre os argumentos apresentados no processo de discussão de empreendimentos turísticos de grande porte no município de Ilha Grande.

São múltiplos os discursos em uma localidade e cada um deles apresenta preocupações diferentes que se opõem ou se complementam. $\mathrm{O}$ discurso do setor público difere do da comunidade local, pois possuem interesses distintos.

Para o governo local o empreendimento traria desenvolvimento econômico uma vez que geraria emprego e renda para a população e já para os membros da comunidade a construção do empreendimento os tiraria de suas terras.

Baseando-se nestes discursos, analisou-se a relação dos diversos atores sobre os temas resorts e desenvolvimento local, pois no processo de discussão do empreendimento turístico Ecocity Brasil foram utilizados tanto argumentos técnicos quanto políticos. Os discursos foram difusos, contraditórios e por vezes vazios, o que mostra claramente a necessidade de fortalecimento político, educativo e ideológico dos representantes dos setores público e privado, dos empreendedores e da comunidade local, no sentido de se politizar mais o processo de discussão, torná-lo mais informativo, comunicativo e participativo. Assim, seria possível avançar em direção a um processo de discussão em que os atores locais estariam mais informados, e abertos a falar, ouvir e ponderar sobre qualquer tema de interesse geral da cidade.

Espera-se que esta pesquisa possa contribuir para discussões futuras sobre o processo de implantanção de resorts em cidades de pequeno porte, servir de propagação para outras pesquisas sobre a relação entre empreendimentos turísticos de grande porte e 
desenvolvimento local, e sobre a participação dos atores sociais no processo de desenvolvimento turístico.

\section{REFERÊNCIAS}

ÁVILA, M. A.; SANTOS, M. da S. Análise da Percepção dos Diferentes Atores Sociais sobre o Desenvolvimento Turístico de Uruçuca - Bahia. In: SEMINÁRIO DA ASSOCIAÇÃO BRASILEIRA DE PESQUISA E PÓS-GRADUAÇÃO EM TURISMO, 6., 2009, São Paulo. Anais... São Paulo: ANPTUR, 2009. p. 1-12. Disponível em:

<http://www.eventos.univerciencia.org/index.php/seminANPTUR/2009/paper/viewFile/ 132/32>. Acesso em: 20/03/2010.

BARBOSA, F. F. O Turismo como Fator de Desenvolvimento Local e/ ou Regional. Caminhos de Geografia, Uberlândia-MG, v. 10, n. 14, p. 107-114, fev. 2005. Disponível em: <www.ig.ufu.br/caminhos_de_geografia.html>. Acesso em: 28/03/2010.

BARROS, P. M. de. Modelo de Planejamento para Implementação e Desenvolvimento do Ecoturismo: Diagnóstico Ecoturístico - Estudo de Caso. Santa Catarina, 1999. 191 p. Dissertação (Mestrado em Engenharia de Produção) Universidade Federal de Santa Catarina, Florianopólis, 1999. Disponível em: <http://www.eps.ufsc.br/disserta99/patricia/cap6a.htm>. Acesso em: 20/05/2010.

CORIOLANO, L. N. M. T. O Turismo Comunitário no Nordeste Brasileiro. In: BARTHOLO, R.; SANSOLO, D. G.; BURSZTYN, I. (Orgs.). Turismo de Base Comunitária diversidade de Olhares e Experiências Brasileiras. Rio de Janeiro: Letra e Imagem, 2009. p. 277-288.

Epistemologia da análise do discurso no turismo. Caderno Virtual de Turismo, v. 5, n.2, p. 50-56, 2005

GÂNDARA, J. M. G.; TORRES, E.; LEFROU, D. A Participação de todos os atores no processo turístico. Revista Virtual de Direito e Turismo, v. 3, n.2, p. 35-36. 2005.

INSKEEP, E.; KALLENBERGER, M. An Integrated Approach to Resort Development: six cases studies. Madri: World Tourism Organization (OMT), 1991.

JR PROJECT MANAGEMENT. Ecocity Brasil Cidade Ecológica. Disponível em: <www.ecocitybrasil.com>. Acesso em: 05/11/2009.

Estudo de Impacto Ambiental (EIA) e Relatório de Impacto Ambiental (RIMA). 2008. 
LAKATOS, E. M.; MARCONI, M. de A. Fundamentos de Metodologia Científica. 6 ed. 3. reimpr. São Paulo: Atlas, 2006.

LOUREIRO, L. V. Resort e Ecoturismo: Sinergia Positiva ou Negativa?. 132 p. Dissertação (Mestrado Profissional em Administração) - Escola de Administração, Universidade Federal da Bahia, Salvador, 2005. Disponível em: <http://www.adm.ufba.br/pub/publicacao/5/MPA/2005/372/leonardo_vasconcellos_lour eiro.pdf>. Acesso em: 10/03/2010.

PÁDUA, E. M. M. de. Metodologia da Pesquisa: abordagem teórico-prática. 10. ed. Campinas, SP: Papirus, 2004.

SEVERINO, A. J. Metodologia do Trabalho Científico. 23. ed. São Paulo: Cortez, 2007.

SILVA, K. M. da; VIEIRA FILHO, N. A. Q. Os Resorts e Seus Impactos nas Comunidades Locais: Estudo de Caso do Treme Lake Resort no Município de Inhaúma em Minas Gerais. Revista OIT, v. 4, n. 3, p. 1-14, set. 2009. Disponível em: <http://virtualbib.fgv.br/ojs/index.php/oit/article/view/1594>. Acesso em: 09/04/2010.

SILVA, M. da G. L. da. Cidades Turísticas: Identidades e Cenários de Lazer. São Paulo: Aleph, 2004.

Recebido em: 11-11-2011.

Aprovado em: 11-12-2011. 